\title{
Revisiting Retrograde Ventriculosinus Shunt as an Alternative for Treating Hydrocephalus in Children
}

\section{Revisitando a derivação ventriculosinusal retrógrada como uma alternativa para tratamento de hidrocefalia em crianças}

\author{
Matheus Fernandes Oliveira ${ }^{1} \quad$ Manoel Jacobsen Teixeira ${ }^{1} \quad$ Marcelo Lima Oliveira $^{1} \quad$ Edson Bor Seng Shu ${ }^{1}$ \\ Fernando Campos Gomes Pinto ${ }^{1}$ \\ ${ }^{1}$ Nuerosurgery Division, Hospital das Clínicas, Faculdade de Medicina, \\ Universidade de São Paulo, São Paulo, São Paulo, Brazil \\ Arq Bras Neurocir 2017;36:108-116. \\ Address for correspondence Matheus Fernandes Oliveira, PhD, \\ Instituto de Assistência Médica ao Servidor Público Estadual, Av. \\ Ibirapuera, 981 - Vila Clementino, 04038-034, São Paulo, SP, Brazil \\ (e-mail: mafernoliv@yahoo.com.br).
}

\begin{abstract}
\section{Keywords}

- hydrocephalus

- ventriculosinus shunt

- treatment

- review
\end{abstract}

Resumo
Introduction Retrograde ventriculosinus shunt (RVSS) is a useful option in the daily routine of neurosurgeons dealing with hydrodynamics. The objective of this manuscript is to review the main data about RVSS.

Methods We performed a critical review. The keywords used were hydrocephalus, shunt, venous sinus, ventriculosinus shunt, retrograde ventriculosinus shunt, and sagittal sinus. The search was performed in the Medline (Pubmed) and EMBASE databases. Results Van Canneyt et al (2008) and Pinto et al (2016) performed experimental studies confirming the effectiveness of RVSS. El Shafei et al $(1985,1987,2001)$ authors reported several cases treated with efficacy and few complications. Oliveira et al (2015, 2016) compared RVSS and ventriculoperitoneal shunt (VPS) in the treatment of hydrocephalus after myelomeningocele repair in infants, with similar functional results. Oliveira et al $(2015,2016)$ also described the applicability of RVSS in situations when VPS is not feasible, or when the peritoneum is not useful.

Discussion Retrograde ventriculosinus shunt is a safe and more physiological option, which requires the use of less prosthetic material. It is feasible and applicable. Especially in children, it generates a normotensive state after shunting, allowing centrifugal head growth, once there is no intracranial hypotension due to overdrainage, which may reflect in long-term better psychomotor development.

Conclusions The surgical technique of RVSS is feasible. The clinical results are comparable with those of the VPS.

Introdução A derivação ventriculosinusal retrógrada (DVSR) deve ser uma opção na rotina de neurocirurgiões que trabalham com hidrodinâmica. O objetivo deste estudo é revisar os principais dados sobre DVSR. received

November 3, 2016

accepted

April 12, 2017

published online

June 12, 2017
DOI https://doi.org/

10.1055/s-0037-1603808.

ISSN 0103-5355.
Copyright (e 2017 by Thieme Revinter

Publicações Ltda, Rio de Janeiro, Brazil

License terms

(c) $(1) \$$ 


\author{
Palavras-chave \\ - hidrocefalia \\ - shunt ventrículo- \\ sinusal \\ - tratamento \\ - revisão
}

Métodos Realizamos uma revisão crítica. As palavras-chave usadas foram hydrocephalus shunt, venous sinus, ventriculosinus shunt, retrograde ventriculosinus shunt, e sagittal sinus. A busca foi feita nas bases de dados Medline (Pubmed) e EMBASE.

Resultados Van Canneyt et al (2008) e Pinto et al (2016) realizaram estudos experimentais confirmando a eficiência do DVSR. El Shafei et al $(1985,1987,2001)$ relataram vários casos tratados com eficiência e poucas complicações. Oliveira et al $(2015,2016)$ compararam DVSR e derivação ventriculoperitoneal (DVP) no tratamento de hidrocefalia após reparo de mielomeningocele em crianças, obtendo resultados funcionais similares. Oliveira et al $(2015,2016)$ também descreveram a aplicabilidade do DVSR em situações em que o DVP não é possível, ou o peritônio é hostil.

Discussão A DVSR é uma opção segura e mais fisiológica, que requer menos material protético; é factível e aplicável. Particularmente em crianças, gera um estado normotenso após o shunt, permitindo crescimento cefálico centrífugo, uma vez que não há mais hipotensão intracraniana devido à hiperdrenagem, o que pode refletir em melhor desenvolvimento psicomotor em longo prazo.

Conclusões A técnica cirúrgica DVSR é viável. Os resultados clínicos se são comparáveis à DVP.

\section{Introduction}

Treating hydrocephalus has always been challenging, especially in children. One century ago, there were no feasible options to treat hydrocephalus, and the natural history of the disease was death by intracranial hypertension or progressive enlargement of the cranial vault in infants. ${ }^{1-7}$

The Twentieth Century witnessed a dramatic change in the comprehension of the disease, the surgical apparatus and the development of materials to enable shunting of the cerebrospinal fluid (CSF) from the ventricles to other sterile body cavities. From neuroendoscopy to shunt valve technologies, we could follow significant changes in the paradigms of the treatment of hydrocephalus. ${ }^{2,8-27}$

However, since the 1990s, a few improvements changed the learning curves and the outcome of the hydrocephalus treatment. Currently, ventriculoperitoneal shunt (VPS) is the mainstay for treatment, as well as endoscopic third ventriculostomy (ETV), which is advocated in specific cases. Over the past decades, shunt revision rates became stable, reaching over $70 \%$ of cases in a lifetime. Endoscopic third ventriculostomy also has known limitations, especially in patients with myelomeningocele and Chiari type II. ${ }^{5-7,28}$

Ventriculosinus shunt (VSS), specifically when performed in a direction opposite to the blood flow, as described by Ismail El Shafei in the 1980's, is a useful option in the daily routine of neurosurgeons dealing with hydrodynamics. Although recent experiences with VSS are scarce, we believe they should be discussed once more and linked to the classic studies by El Shafei. ${ }^{6,7,29-31}$

The objective of this manuscript is to discuss new clinical data about retrograde ventriculosinus shunt (RVSS) and link them to the pertinent literature.

\section{Methods}

We performed a critical review to address the application, advantages and disadvantages of RVSS to treat hydrocephalus, especially in children. The keywords used were hydrocephalus, shunt, venous sinus, ventriculosinus shunt, retrograde ventriculosinus shunt, and sagittal sinus. The search was performed in the Medline (Pubmed) and EMBASE databases.

All manuscripts were included. A review of the retrieved references was also performed to find crossed references. Any references known by the authors were also included.

\section{Results}

Since Toma et $\mathrm{al}^{5}$ published a full review about VSS in 2010, only 5 manuscripts updated the subject, 1 by El-Shafei et al, and 4 by Oliveira et al and Pinto et al. In the present article, we discuss the evolution of the technique and its current results. $6,8,10,22,25,28,32-34$

\section{Review}

Gartner, in 1896, suggested that the most physiological way to treat hydrocephalus would be a connection of the ventricles with the venous blood system of the head and neck. Portnoy proposed that the perfect system to treat hydrocephalus would be the one that allowed for CSF drainage, could keep intracranial pressure (ICP) normal, and would not cause complications. $3,5,14,20,26,27$

Ventriculoperitoneal shunt (VPS) is the preferred option to treat hydrocephalus, even though it has a revision rate of more than $70 \%$ of patients throughout their lifetime, and of $30 \%$ of patients in the first year. An important complication is the siphoning phenomenon, which leads to over drainage and subdural effusions. ${ }^{35,36}$ 
Siphoning leads to over drainage of the intracranial CSF into the distal site when the patient with VPS is in the orthostatic position. To solve this problem, anti-siphoning devices (ASDs) were added to the VPS line, increasing the pressure of the drainage system as the patient raises the head, thus decreasing the drainage of the CSF. Some of them include gravitational devices, which change the pressure of the whole liquid column according to a range of head positions, allowing different grades of additional pressure. However, such solutions did not eliminate the hydrodynamic phenomenon of siphoning, and significantly increased the cost of the prosthesis. ${ }^{8-18,29,32-44}$

In the beginning of the XXI century, Aschoff stated that there were more than 300 shunt systems available; however, none could reach what was proposed by Gartner and Portnoy. Several sites to perform the shunt were also tried, from the gallbladder to the bladder, but the peritoneal cavity was the site in which the procedure reached higher accuracy and effectiveness. ${ }^{5}$

In the 1940's, Ingraham induced hydrocephalus in dogs and performed treatment with an anterograde ventriculojugular shunt; however, the distal end of the catheter obstructed due to siphoning. When positioning the catheter against the blood flow, the catheter flow would be laminar, and there would be no turbulence zone, which would prevent blood clotting and catheter obstruction. ${ }^{14}$

This hemodynamic principle was demonstrated in the studies by El Shafei and El-Rifaii. Another principle that was also demonstrated by these authors was the fact that the internal jugular vein, which collapses in the orthostatic position, has the capacity to work as a physiological antisiphoning system. Thus, to use this natural property, any ventriculovenous shunt catheter should have the distal extremity located proximally to the internal jugular vein, in the opposite direction of the blood stream. Thus, there is an improvement in hemodynamics with the removal of the regions of turbulence, and the avoidance of back flow and thrombosis (-Fig. 1). $)^{8,29,32-34,40-44}$

\section{RVSS Technique and Variations}

El-Shafei et al pioneered the technique by performing a puncture in the retrograde direction of the blood flow in the superior sagittal sinus (SSS) using the pressure impact of the blood flow in the dural sinuses to maintain the CSF pressure greater than the dural sinus pressure, regardless of changes in posture or intrathoracic pressure (-Fig. 2). These authors modified their technique later by adding a valve of very low pressure, recognizing that, in the event of a reduction in intracranial pressure (ICP) due to lumbar puncture or sudden change of heart output, some retrograde flow of venous blood to the distal catheter could hinder the shunt. They also broke new ground by using transcranial Doppler (TCD) data to indirectly evaluate cerebral hydrodynamics through the cerebral blood flow velocities. ${ }^{8,29,32-34,40-44}$

The surgical technique as described by El-Shafei et al involves two cranial burr holes in the same arcuate incision in the scalp on the parietal region. One burr hole is in the posterior parietal bone (Frazier point), and the other, in the middle third of the sagittal sinus. A small opening is made in the dura mater of the parietal incision, the lateral ventricle is
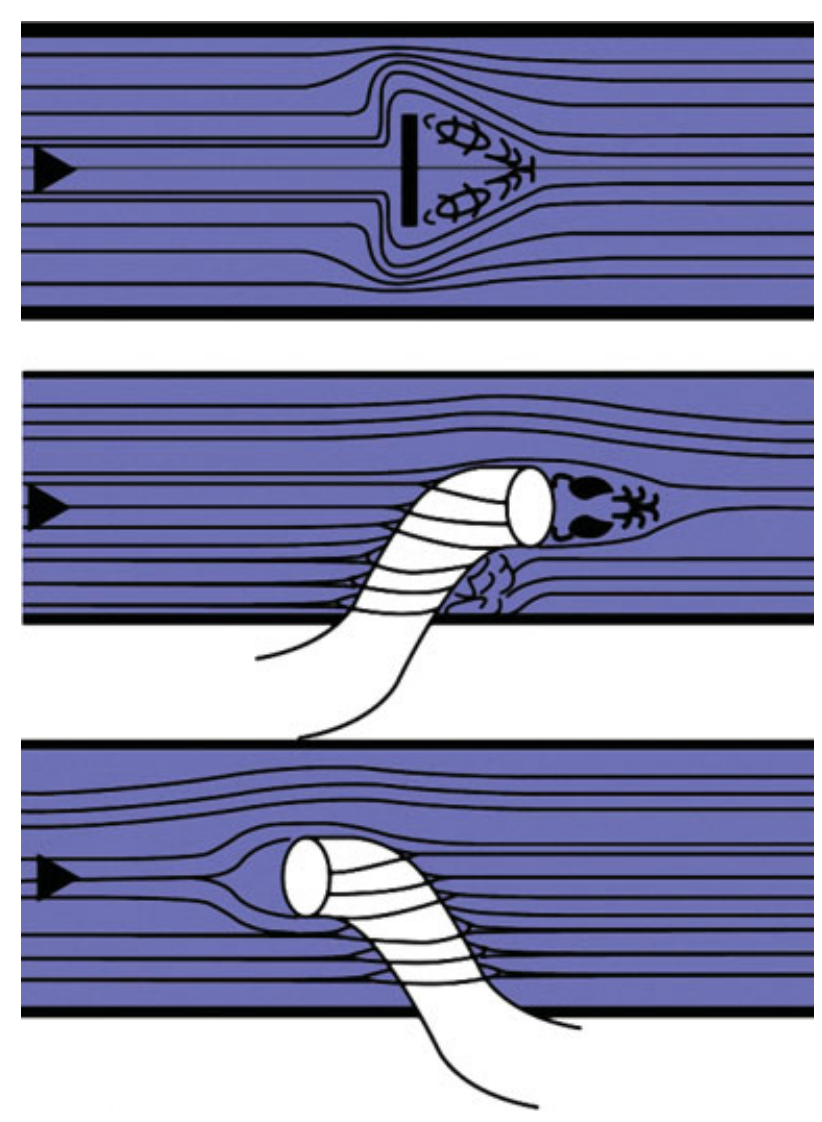

Fig. 1 In the upstream region of the obstacle, there will be an impact zone, whereas in the downstream region, there will be a weak zone.

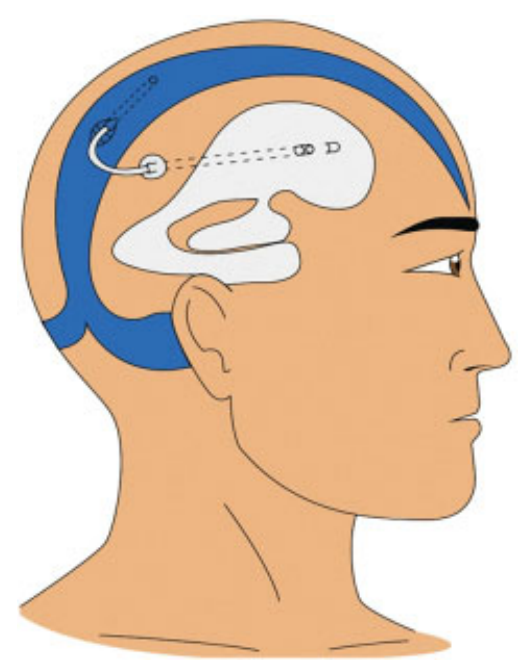

Fig. 2 RVSS design.

punctured, and then, a small opening is made in the sagittal sinus, and the catheter is inserted $\sim 2 \mathrm{~cm}$ against the direction of the blood flow ( - Fig. 3). El-Shafei et al published the results with the use of a single catheter and with the association of a very low pressure gradient valve (just to add another mechanism to avoid back flow). $8,29,32-34,40-44$

In the small but increasing experience of our group, we have adopted the classic technique by El-Shafei et al with a valveless 


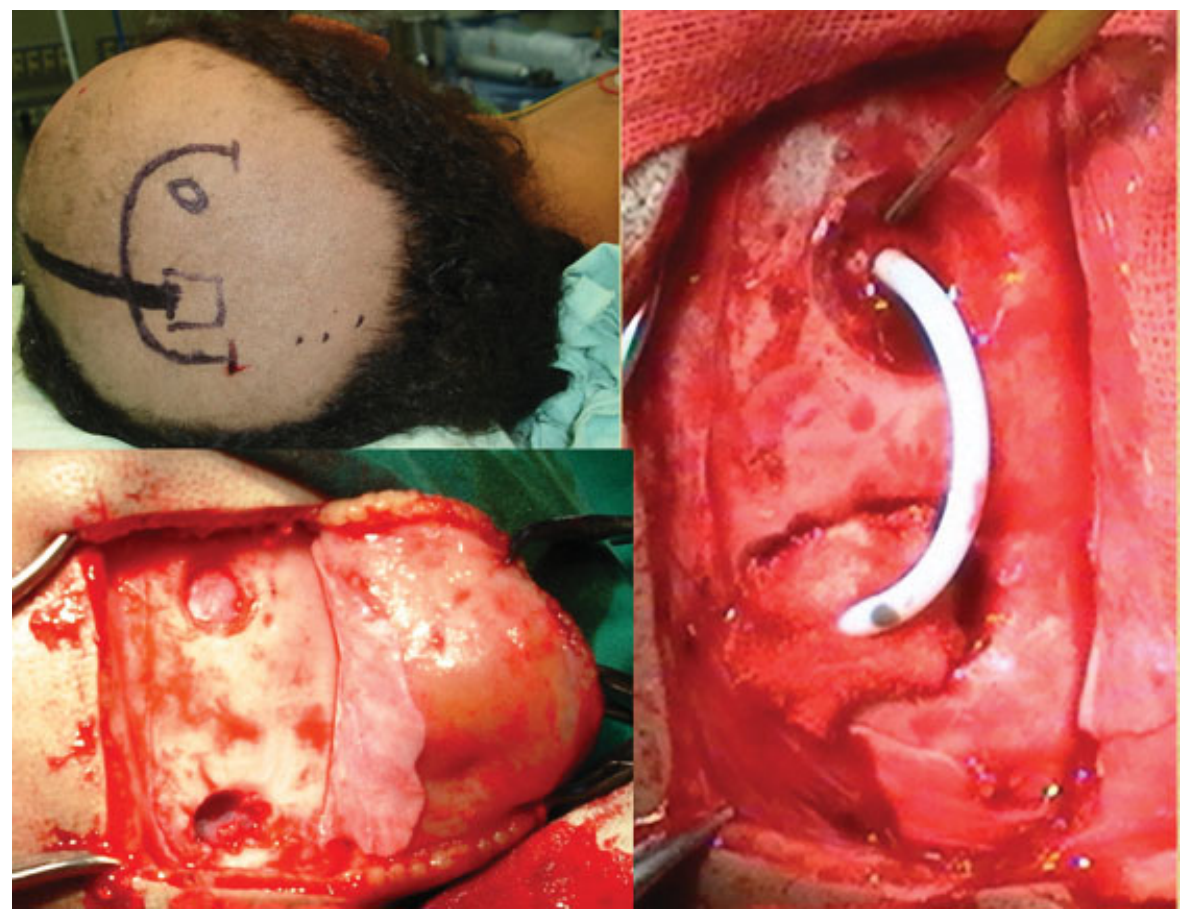

Fig. 3 Phases of the surgical technique. Positioning and arcuate incision. Opening with medial and lateral burr holes. Catheterization of lateral ventricle and superior sagittal sinus. Hemostasis. Closure with pericranium and skin closure.

catheter. However, in adult patients, we have changed landmarks for ventricular and superior sagittal sinus (SSS) puncture. We used a frontal incision to enable the puncture in Kocher's point, and another incision over the SSS to allow for1 burr hole in the middle third of the sagittal sinus, $\sim 3 \mathrm{~cm}$ behind the bregma. The lateral ventricle is punctured, and then a small opening is made in the SSS, and the catheter is inserted $\sim 2 \mathrm{~cm}$ against the direction of the blood flow. The catheter used to perform the shunt is, by convenience, the PS Medical valve (Medtronic, Dublin, Ireland) ventricular catheter, which is already in routine use at our institution. The ventricular catheter is the only one applied without the use of a valve system (-Fig. 4). 10,21,22

Another potential option designed by our group, but with limited application until now, is the fragmentation of the catheter in two parts: one catheter for the ventricular puncture, and another for the SSS puncture. Then, the margin of one catheter has a connector to allow the connection of both catheters. The last variation with no clinical applications described in the literature is a combination of two catheters of different diameters connected as described before ( - Fig. 5). Using this rationale, it would be possible

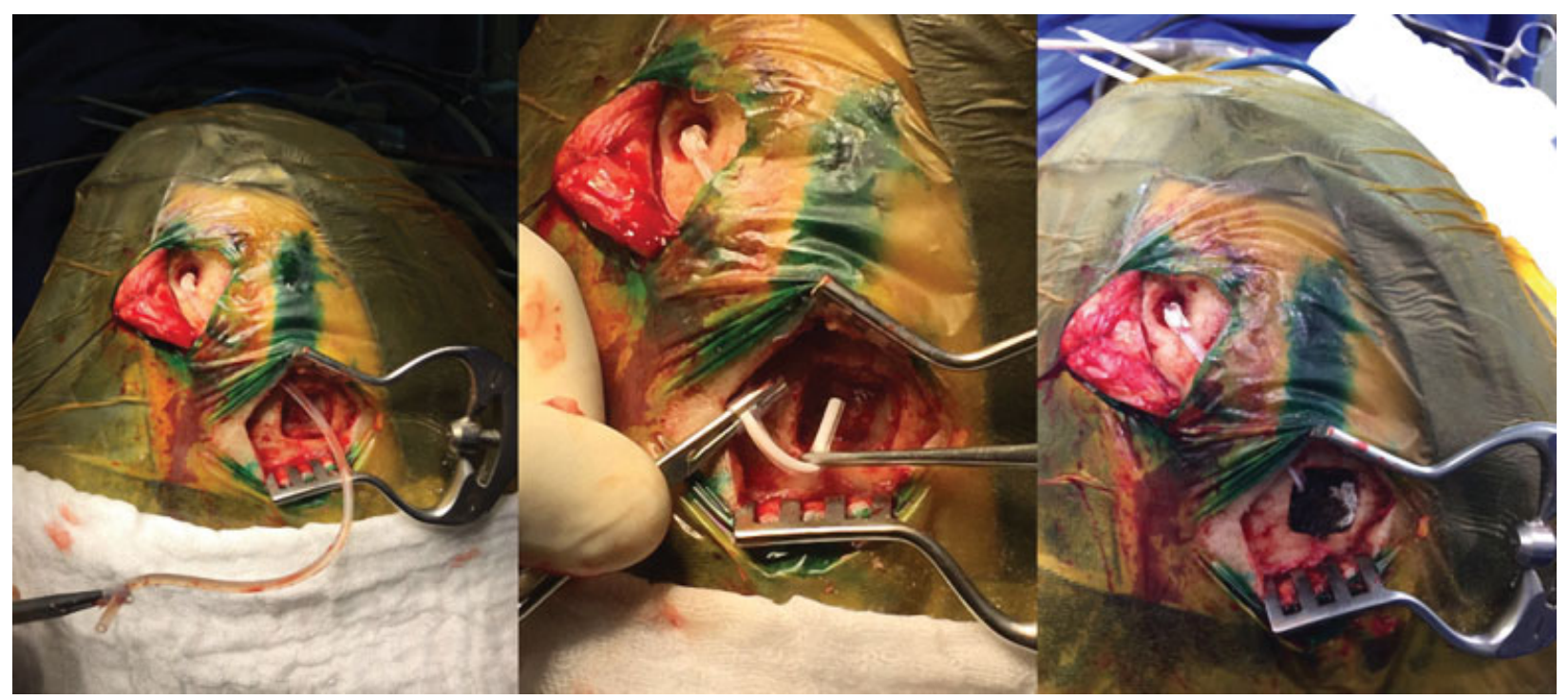

Fig. 4 Retrograde ventriculosinus shunt after failed ventriculoperitoneal shunt. Left ventricular puncture followed by burr hole over the SSS and puncture. 

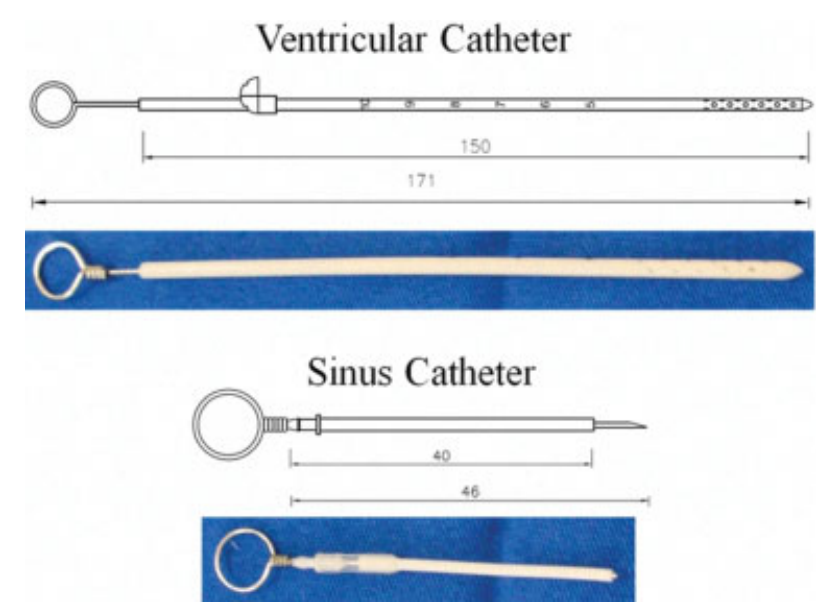

Fig. 5 Option for retrograde ventriculosinus shunt catheter, with two catheters of different diameters connected.

to increase or decrease flow resistance and, therefore, the risk of back flow. However, these ideas should be further discussed in experimental and clinical bases. ${ }^{10,21,22}$

\section{Experimental Basis for RVSS}

Van Canneyt et al performed an experimental study to analyze RVSS. Firstly, an experimental model of the cerebral ventricles, the arachnoid villi, the cortical veins, and the SSS was built. Secondly, a numerical model of the cortical veins and the SSS was built. No over drainage was found in the antegrade or the retrograde positions of the shunt. Blood reflow was only found while mimicking lumbar puncture or changes in position with the experimental model (lowering the intracranial pressure or increasing the sinus pressure rapidly). These authors suggested that the main advantages of this method include short length of derivation and prevention of siphoning. After an experimental analysis, they concluded that when the catheter is placed in an anterograde manner, the pressure at the catheter tip is $3.3 \mathrm{~Pa}$, which is lower than that of the SSS. In the backward position, the catheter tip pressure was $16.7 \mathrm{~Pa}$, serving as a protection against overdrainage. ${ }^{6,12-15,25,26}$

Pinto et al proposed and designed an animal experimental model for RVSS using mongrel dogs and inducing hydrocephalus with kaolin. They stated that the RVSS technique was feasible and even simple, not requiring a large learning curve. ${ }^{25}$

In the dogs with the RVSS model, they could successfully induce hydrocephalus and its clinical features. The surgical procedure finished with no remarks, however they failed to predict that the external diameter of the catheter used $(2.5 \mathrm{~mm})$ would prevent the normal blood flow through the SSS, which also has a $2.5 \mathrm{~mm}$ caliber, resulting in cerebral venous infarction due to venous blood stasis and drainage blocking of the hypertensive CSF accumulated in the ventricles (-Fig. 6). Thus, they proposed changing the external diameter of the catheter to adapt to canine anatomy and proportions. ${ }^{25}$

\section{Clinical Basis for RVSS}

El Shafei is surely the most important name in the experimental and clinical development of RVVSs. The first article he published (along with another author) in 2001 included 56

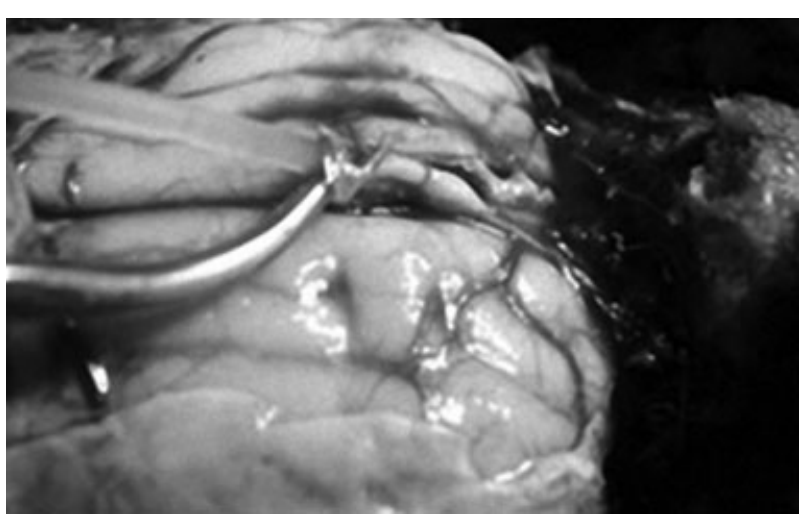

Fig. 6 Catheterization of the superior sagittal sinus (SSS) in a canine model of retrograde ventriculosinus shunt. The catheter had almost the same diameter as the SSS, so there was venous blockage and infarction.

patients and was followed by a second article with other authors in 2005, which included 54 patients, producing a total of 110 patients reviewed retrospectively; 99 patients had valveless catheters, and 11 had catheters with low pressure valves..$^{8-13,29,32-34,40-44}$

In 2010, they published the last experience. During the past 40 years, 229 RVVSs were implanted; 219 patients (95.63\%) benefited from the shunt, and only 2 of them needed a single shunt revision. The manifestations of increased intracranial pressure disappeared, different degrees of regression of the ventriculomegaly occurred in patients with closed craniums, but not in infants and young children with open craniums, and there were no problems related to improper CSF drainage or venous thrombosis. The follow-up period is of up to 40 years (mean 9 years 8 months). ${ }^{8-13,29,32-34,40-44}$

El-Shafei showed that, in children, the clinical improvement occurred immediately after shunt insertion with normotensive fontanelle and disappearance of the hairy scalp engorged veins, with gradual relief of eye signals. The psychomotor development of the patients was satisfactory. ${ }^{8-12,29,32-34,40-44}$

Paul C. Sharkey, in 1965, published his experience with 4 pediatric patients. Fourteen years later, in 1979, Cecil J. Hash published a series of 36 procedures. And Wen reported 15 cases of obstructive hydrocephalus in 1965, and then changed his technique in 52 patients in the pediatric age group, and published the results in $1982 .{ }^{5}$

Børgesen, Gjerris and Agerlin also applied the technique. The first series was published in 2001. The second article was published in 2004 with two extra authors, and included the follow-up results of 45 patients from Denmark, Italy and Norway. ${ }^{1,5,45}$

Most series treated all kinds of hydrocephalus in children and adults of all age groups. However, cases of spina bifida were excluded. All authors reported clinical and radiological improvement. The clinical findings, such as headache, nausea, vomiting and papilledema changed after the surgery. ${ }^{5}$

The follow-up period and shunt revisions were variable. The revision rate varied between $11.8 \%$ and $37.5 \%$. Most patients had a shorter follow-up period. In healthy young children, brain growth causes an increase in the thickness of the cerebral 


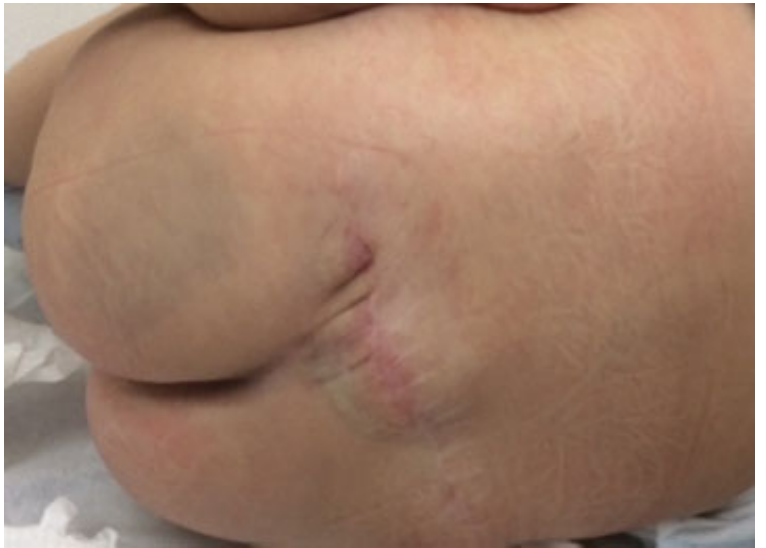

Fig. 7 Post-operative aspect of a surgically repaired myelomeningocele.

mantle and head circumference, while the ventricular size remains stable, that is, in normal situations, the strength of the brain wraps is lower than the CSF pressure, allowing centrifugal growth. ${ }^{1}$

The last review on the subject showed that among 265 patients, there were no reports of sinus thrombosis, air embolism, uncontrollable operative bleeding or nephritis associated with the shunt. ${ }^{5}$

\section{RVSS versus VPS in Hydrocephalus after Myelomeningocele Repair}

Myelomeningocele is a neural tube defect in neurulation embryonic stage by the third week of life. Its incidence may reach 1-2 per 1,000 live births. Even with all advances in intrauterine and postnatal management, up to $90 \%$ of these patients may present hydrocephalus in different degrees, requiring treatment (-Fig. 7 ). Ventriculoperitoneal shunt and ETV are classic options, but revisions rates are high in VPS; ETV still has a limited success in cases of Chiari II, especially in younger infants. 7,16,23,46

Oliveira et al compared RVSS and VPS in a randomized trial with preliminary results. A total of 9 patients were included in the study for a period of 2 years. Four patients were allocated to the control group (VPS), and 5 patients to the RVSS group. Transcranial Doppler was used to analyze indirect hydrodynamic patterns, as reported previously by El-Shafei. ${ }^{27,47,48}$

The follow-up included evaluations of the cephalic perimeter $(\mathrm{CP})$, bregmatic fontanelle, TCD, computed tomography, neuropsychomotor development, complications and shunt revision, and outcomes focused on patients and caregivers. ${ }^{22}$

The cephalic perimeter, the tomography and the fontanelle were characteristic in each group. In the RVSS group, there was no abrupt reduction in head circumference after surgery. The $\mathrm{CP}$ assumed a physiologic contour, but remained high. In control group, the $\mathrm{CP}$ reduced abruptly after surgery, with subsequent regrowth. Similarly, the fontanelle in the RVSS group remained normotensive, meaning cranial normotension. In the control group, they became normotensive or hypotensive, especially in older children, and could imply a siphoning component in older children with a more upright posture (-Figs. 8 and $\mathbf{9}$ ). ${ }^{22}$

The TCD showed significant improvements in cerebral hemodynamics parameters after treatment in both groups,

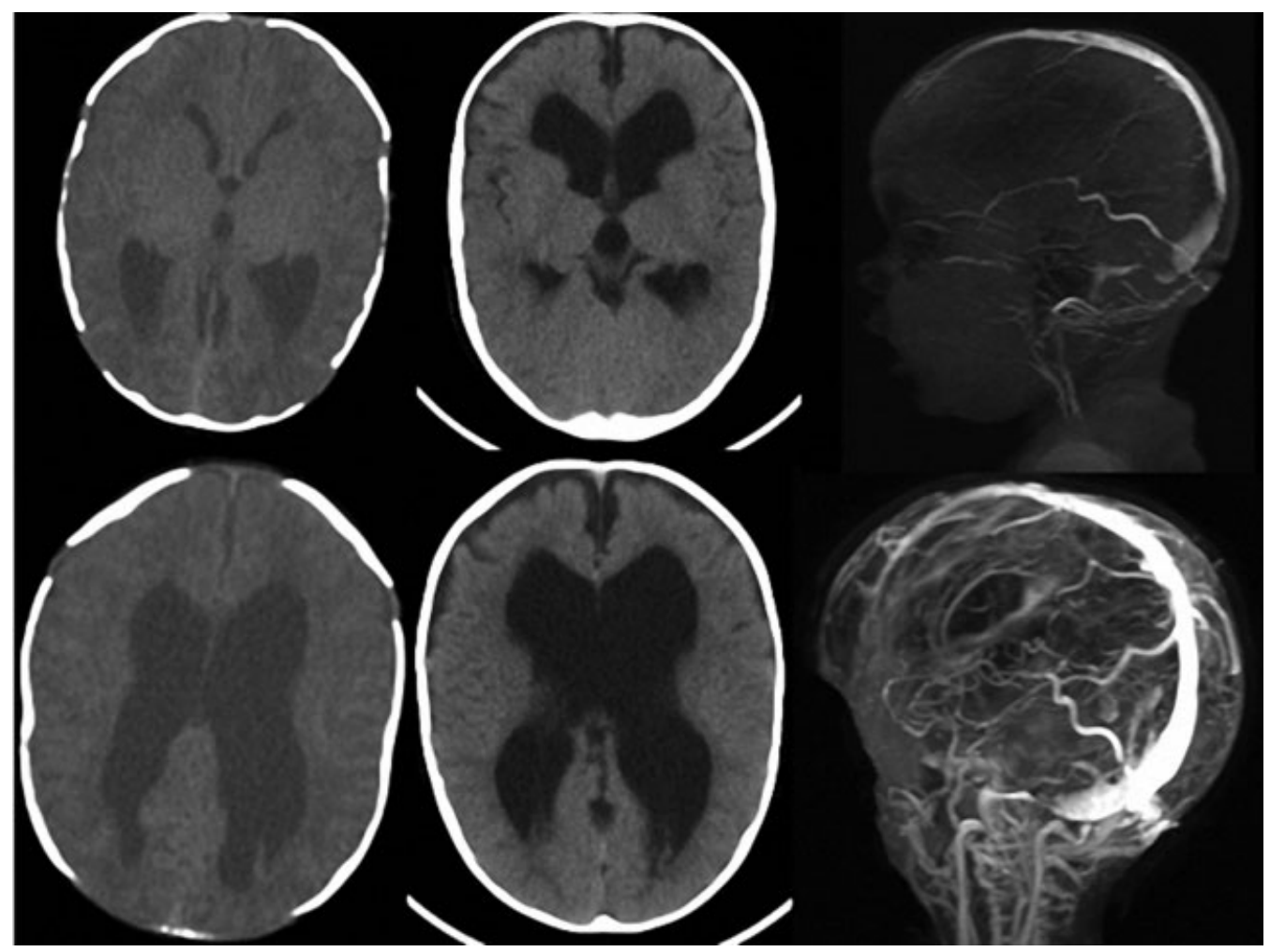

Fig. 8 Pre-operative evaluation before retrograde ventriculosinus shunt. Normal ventricular size at the age in months. Hydrocephalus at the age of 6 months. Normal sinus anatomy. 


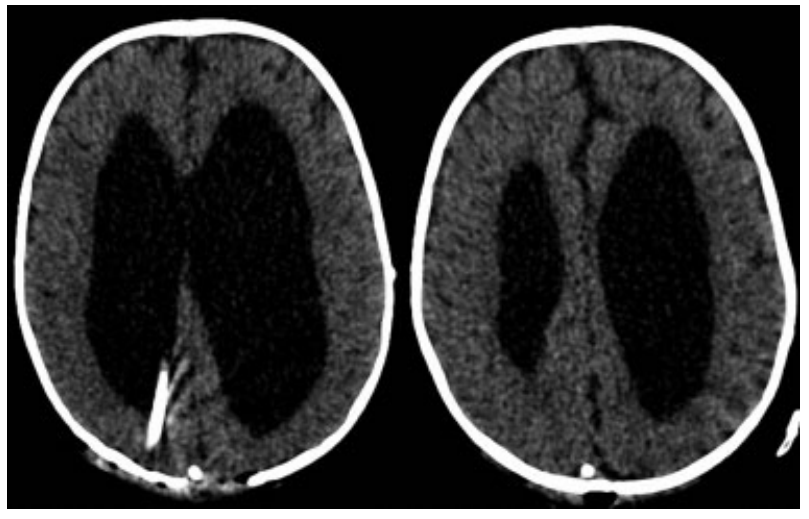

Fig. 9 Postoperative retrograde ventriculosinus shunt evaluation. There is no clear decrease in ventricular size. with decreased velocity of intracranial vessels and a decrease in the pulsatility and resistance indexes (-Figs. 10 and 11). There were no differences between VPS and RVSS. The TCD associated with clinical and physical examinations proved to be a safe and appropriate tool to assess dysfunction of RVSS. $^{6,7,22,30,31}$

In the RVSS group, there was need for one revision and one conversion to VPS. In VPS group there was no revision or complications. Psychomotor development after surgery was similar in both groups. However, further evaluation is needed with specific neuropsychological tests which can detect subtle changes. ${ }^{22}$

\section{RVSS and Failed VPS}

Peritoneal cavity alterations are one of the most frequent causes of VPS failure, due to the formation of primary or secondary adhesions, fibrosis, ascites, cysts, pseudocysts and peritonitis. ${ }^{10}$ Although there are other second options, like ventriculopleural and ventriculoatrial, they may be useful, but they are potentially harmful. ${ }^{10}$

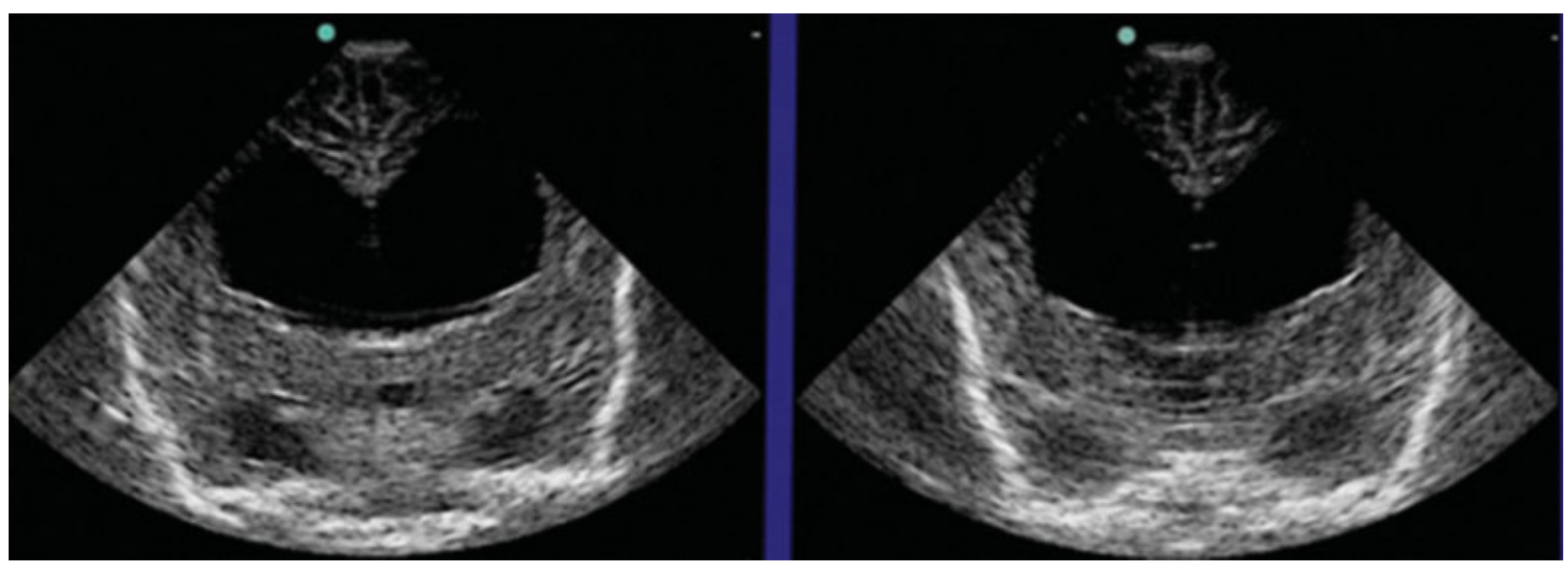

Fig. 10 Duplex evaluating ventricular size. There is no clear ventricular size decrease before (left) and after (right) retrograde ventriculosinus shunt.
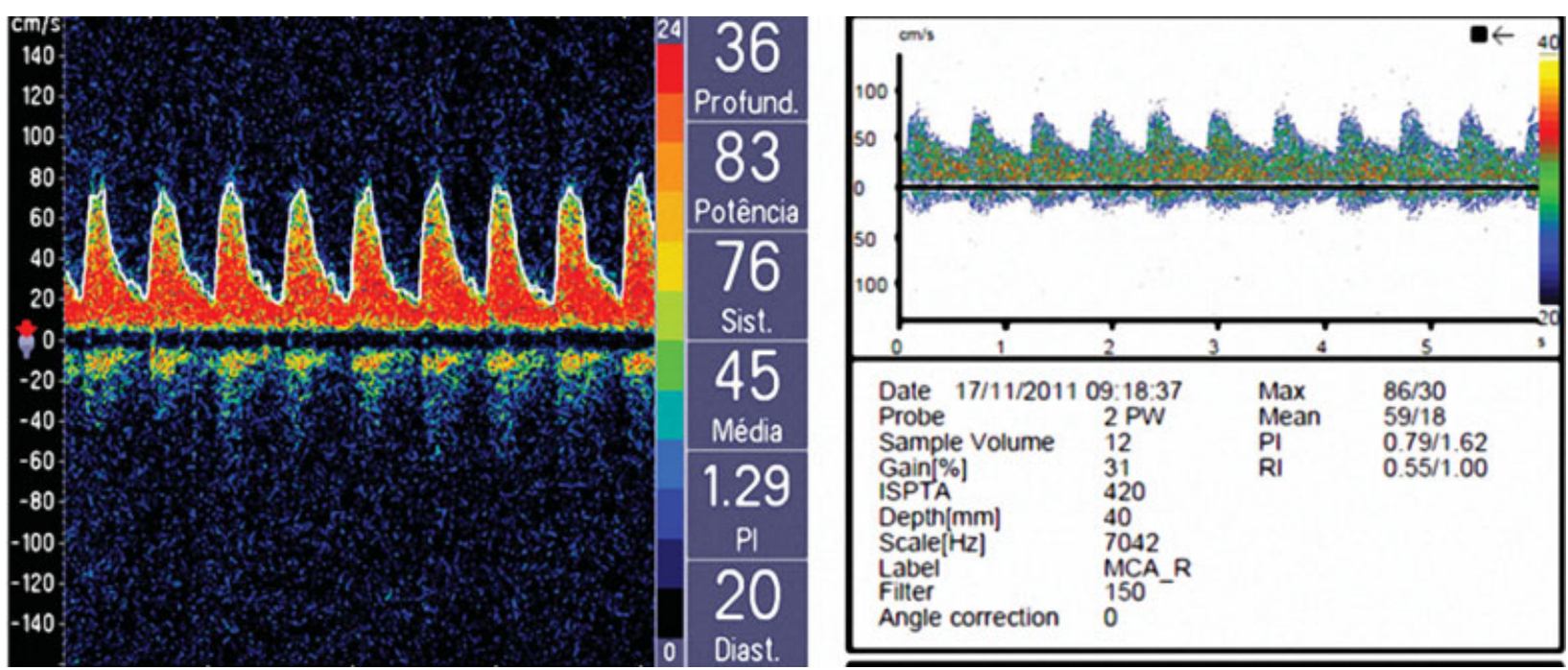

Fig. 11 Transcranial Doppler (TCD) of a retrograde ventriculosinus shunt (RVSS) patient. Pre-operative and postoperative TCD. Postoperative mean velocities in middle cerebral artery (MCA) decreased after RVSS, and there was a decrease in pulsatility index (PI). 
Oliveira et al described three cases of RVSS applied in situations when VPS is not feasible, or the peritoneum is not useful. In one case, there was refractory ascites; in another, a peritonitis, and in the last, pseudocyst formation. In all three cases, the patients were adults and tolerated RVSS to treat the underlying hydrocephalus. One patient needed revision surgery to reposition the catheter, which was not inside the SSS. Although applied in adults, this experience also sheds light over the potential use of RVSS in children with a hostile peritoneum. $^{10}$

\section{Discussion}

Retrograde ventriculosinus shunt is a safe and more physiological option that requires the use of less prosthetic material. It is feasible and applicable, as long as there is pervious SSS to allow drainage of excessive CSF. It uses a natural antisiphon device (internal jugular vein), and enables CSF drainage inside the venous system. Manipulation of the SSS is safer than usually believed, and one important matter is that the dural opening for the ventricular puncture should be just enough to catheterize the ventricle and avoid creating CSF leakage. ${ }^{8-24,29,32-34,40-44}$

The main advantages are the use of less prosthetic material, the safety and efficacy, respecting hydrodynamics and avoiding over drainage. The main disadvantages are: the necessary learning curve and the possibility of retrograde flow if a lumbar puncture is performed (which can be solved if a low-pressure valve is added to the shunt system). Complications like dysfunction and infection are not common, and overdrainage is an unlikely event. $8,29,32-34,40-44$

In RVSS, although there is no immediate and marked ventricular size decrease (which is common in VPS), there is stable ventricular size with improved hemodynamics and hydrodynamics revealed by a decrease in the pulsatility index (PI) after surgery, which is maintained in the late follow-up. In patients with increased PI there was also clinical impairment, which was indicative of the need of a revision surgery. ${ }^{8,29,32-34,40-44,49}$

Especially in children, RVSS generates a normotensive state after shunting, allowing centrifugal head growth, once there is no intracranial hypotension due to over drainage, which may reflect in long-term better psychomotor development. Additionally, there is no need to operate the abdomen, avoiding complications of disabsortive peritoneum. ${ }^{12-24,49}$

In our sample, TCD was used successfully for diagnostic and follow-up evaluation of hemodynamics and hydrodynamics in the pre- and postoperative phases of RVSS. It was technically feasible in all patients, correlated closely with other clinical and imaging parameters, and was sensitive for the identification of system malfunction. ${ }^{49}$

\section{Conclusions}

The surgical technique of RVSS is feasible. The clinical results are comparable with those of VPS. To date, we believe it should be performed especially after myelomeningocele repair in young infants, and as an alternative to failed VPS after multiple revisions.

Conflicts of Interest

The authors have no conflicts of interest to report.

\section{References}

1 Børgesen SE, Gjerris F, Agerlin N. Shunting to the sagittal sinus. Acta Neurochir Suppl (Wien) 2002;81:11-14

2 Rainov NG, Weise JB, Burkert W. Transcranial Doppler sonography in adult hydrocephalic patients. Neurosurg Rev 2000; 23(01):34-38

3 Rekate HL. Selecting patients for endoscopic third ventriculostomy. Neurosurg Clin N Am 2004;15(01):39-49

4 Samadani U, Mattielo JA, Sutton LN. Ventriculosagittal sinus shunt placement: technical case report. Neurosurgery 2003;53(03): 778-779, discussion 780

5 Toma AK, Tarnaris A, Kitchen ND, Watkins LD. Ventriculosinus shunt. Neurosurg Rev 2010;33(02):147-152, discussion 153

6 Van Canneyt K, Kips J, Mareels G, Baert E, Van Roost D, Verdonck P. Experimental and numerical modelling of the ventriculosinus shunt (El-Shafei shunt). Proc Inst Mech Eng H 2008;222(04):455-464

7 Warf BC. Hydrocephalus associated with neural tube defects: characteristics, management, and outcome in sub-Saharan Africa. Childs Nerv Syst 2011;27(10):1589-1594

8 el-Shafei IL. Ventriculovenous shunt against the direction of blood flow: a new approach for shunting the cerebrospinal fluid to the venous circulation. Childs Nerv Syst 1985;1(04):200-207

9 Faggin R, Bernardo A, Stieg P, Perilongo G, d'Avella D. Hydrocephalus in infants less than six months of age: effectiveness of endoscopic third ventriculostomy. Eur J Pediatr Surg 2009; 19(04):216-219

10 Oliveira MF, Teixeira MJ, Reis RC, Petitto CE, Gomes Pinto FC. Failed Ventriculoperitoneal Shunt: Is Retrograde Ventriculosinus Shunt a Reliable Option? World Neurosurg 2016;92:445-453

11 Fox JL, McCullough DC, Green RC. Effect of CSF shunt on ICP and CSF dynamics. II. A new technique of pressure measurement, results and concepts. J Neurol Neurosurg Psychiatry 1973; 30:302-312

12 Gupta N, Park J, Solomon C, Kranz DA, Wrensch M, Wu YW. Longterm outcomes in patients with treated childhood hydrocephalus. J Neurosurg 2007;106(5, Suppl)334-339

13 Hash CJ, Shenkin HA, Crowder LE. Ventricle to sagittal sinus shunt for hydrocephalus. Neurosurgery 1979;4(05):394-400

14 Ingraham FD, Matson DD, Alexander F Jr, Woods RP. Studies in the treatment of experimental hydrocephalus. J Neuropathol Exp Neurol 1948;7(02):123-143

15 Jindal A, Mahapatra AK. Correlation of ventricular size and transcranial Doppler findings before and after ventricular peritoneal shunt in patients with hydrocephalus: prospective study of 35 patients. J Neurol Neurosurg Psychiatry 1998;65(02):269-271

16 Kadri H, Mawla AA. Variations of endoscopic ventricular anatomy in children suffering from hydrocephalus associated with myelomeningocele. Minim Invasive Neurosurg 2004;47(06):339-341

17 Kestle JR, Walker MLJ; Strata Investigators. A multicenter prospective cohort study of the Strata valve for the management of hydrocephalus in pediatric patients. J Neurosurg 2005;102(2, Suppl)141-145

18 Kondageski C, Thompson D, Reynolds M, Hayward RD. Experience with the Strata valve in the management of shunt overdrainage. J Neurosurg 2007;106(2, Suppl)95-102

19 Lo P, Drake JM. Shunt malfunctions. Neurosurg Clin N Am 2001; 12(04):695-701, viii 
20 Nulsen FE, Spitz FB. Treatment of hydrocephalus by direct shunt from ventricle to jugular vein. Surg Forum Am Coil Surg 1951; 2:399-408

21 Oliveira MF, Saad F, Reis RC, Rotta JM, Pinto FC. Programmable valve represents an efficient and safe tool in the treatment of idiopathic normal-pressure hydrocephalus patients. Arq Neuropsiquiatr 2013;71(04):229-236

22 Oliveira MF, Teixeira MJ, Norremose KA, et al. Surgical technique of retrograde ventricle-sinus shunt is an option for the treatment of hydrocephalus in infants after surgical repair of myelomeningocele. Arq Neuropsiquiatr 2015;73(12):1019-1025

23 Pavez A, Salazar C, Rivera R, et al. Description of endoscopic ventricular anatomy in myelomeningocele. Minim Invasive Neurosurg 2006;49(03):161-167

24 Pinto FC, Pereira RM, Saad F, Teixeira MJ. Performance of fixedpressure valve with antisiphon device SPHERA( $\left({ }^{\circledR}\right)$ in hydrocephalus treatment and overdrainage prevention. Arq Neuropsiquiatr 2012;70(09):704-709

25 Pinto FCG, Becco R, Alho EJL, et al. The retrograde ventriculo-sinus shunt in an animal experimental model of hydrocephalus. Pediatr Neurosurg 2016;51(03):142-148

26 Portnoy HD, Schulte RR, Fox JL, Croissant PD, Tripp L. Anti-siphon and reversible occlusion valves for shunting in hydrocephalus and preventing post-shunt subdural hematomas. J Neurosurg 1973; 38(06):729-738

27 Pudenz RH, Russell FE, Hurd AH, Shelden CH. Ventriculo-auriculostomy; a technique for shunting cerebrospinal fluid into the right auricle; preliminary report. J Neurosurg 1957;14(02):171-179

28 Teo C, Jones R. Management of hydrocephalus by endoscopic third ventriculostomy in patients with myelomeningocele. Pediatr Neurosurg 1996;25(02):57-63, discussion 63

29 El Shafei IL, El Shafei HI. The retrograde ventriculo-sinus shunt (El Shafei RVS shunt). Rationale, evolution, surgical technique and long-term results. Pediatr Neurosurg 2005;41(06):305-317

30 Wen HL. Ventriculo-superior sagittal sinus shunt for hydrocephalus. Surg Neurol 1982;17(06):432-434

31 Zemack G, Romner B. Seven years clinical experience with the Codman Hakim programmable valve: a retrospective study of 583 patients. J Neurosurg 2000;92:941-948

32 el-Shafei IL, el-Rifaii MA. Ventriculojugular shunt against the direction of blood flow. II. Theoretical and experimental basis for shunting the cerebrospinal fluid against the direction of blood flow. Childs Nerv Syst 1987;3(05):285-291

33 el-Shafei IL, el-Rifaii MA. Ventriculojugular shunt against the direction of blood flow. I. Role of the internal jugular vein as an antisiphonage device. Childs Nerv Syst 1987;3(05):282-284

34 El-Shafei IL, El-Shafei HI. The retrograde ventriculosinus shunt: concept and technique for treatment of hydrocephalus by shunting the cerebrospinal fluid to the superior sagittal sinus against the direction of blood flow. Preliminary report. Childs Nerv Syst 2001;17(08):457-465, discussion 466

35 Browd SR, Ragel BT, Gottfried ON, Kestle JR. Failure of cerebrospinal fluid shunts: part I: Obstruction and mechanical failure. Pediatr Neurol 2006;34(02):83-92

36 Browd SR, Gottfried ON, Ragel BT, Kestle JR. Failure of cerebrospinal fluid shunts: part II: overdrainage, loculation, and abdominal complications. Pediatr Neurol 2006;34(03):171-176

37 Choux M, Camboulives J, Rigaut F. [Prevention of infections in ventriculoperitoneal shunts in children]. Ann Fr Anesth Reanim 1992;11(06):699-704

38 de Souza RB, Pinto FC. Could craniometric measurements explain the growth of the superior sagittal sinus? Pediatr Neurosurg 2012;48(04):225-228

39 Eklund A, Koskinen LO, Malm J. Features of the Sinushunt and its influence on the cerebrospinal fluid system. J Neurol Neurosurg Psychiatry 2004;75(08):1156-1159

40 El Shafei IL. Ventriculo-venous shunt to the proximal segment of an occluded neck vein. A new method for shunting the cerebrospinal fluid to the venous circulation. Surg Neurol 1975;3(05):237-244

41 El Shafei IL. Ventriculovenous shunt to the proximal segment of a ligated neck vein. A new surgical technique for shunting the cerebrospinal fluid to the venous circulation (preliminary report). Childs Brain 1975;1(05):311-323

42 Elgamal EA. Natural history of hydrocephalus in children with spinal open neural tube defect. Surg Neurol Int 2012;3:112

43 El-Shafei IL, El-Shafei HI. The retrograde ventriculovenous shunts: the El-Shafei retrograde ventriculojugular and ventriculosinus shunts. Pediatr Neurosurg 2010;46(03):160-171

44 el-Shafei IL. Ventriculojugular shunt against the direction of blood flow. III. Operative technique and results. Childs Nerv Syst 1987; 3(06):342-349

45 Børgesen SE, Pieri A, Cappelen J, Agerlin N, Gjerris F. Shunting to the cranial venous sinus using the SinuShunt. Childs Nerv Syst 2004;20(06):397-404

46 Adzick NS, Thom EA, Spong CY, et al; MOMS Investigators. A randomized trial of prenatal versus postnatal repair of myelomeningocele. N Engl J Med 2011;364(11):993-1004

47 Alexandrov AV, Sloan MA, Tegeler $\mathrm{CH}$, et al; American Society of Neuroimaging Practice Guidelines Committee. Practice standards for transcranial Doppler (TCD) ultrasound. Part II. Clinical indications and expected outcomes. J Neuroimaging 2012;22(03):215-224

48 Behrens A, Lenfeldt N, Ambarki K, Malm J, Eklund A, Koskinen LO. Transcranial Doppler pulsatility index: not an accurate method to assess intracranial pressure. Neurosurgery 2010;66(06):1050-1057

49 de Oliveira MF, Teixeira MJ, de Lima Oliveira M, Seng-Shu EB, Norremose KA, Gomes Pinto FC. Transcranial Doppler in the evaluation of infants treated with retrograde ventriculosinus shunt. Childs Nerv Syst 2016;32(11):2133-2142 